\title{
Adipocytokines and endothelial function in preeclamptic women
}

\author{
Toshitaka Mori, Koichi Shinohara, Akihiko Wakatsuki, Kazushi Watanabe and Ai Fujimaki
}

Visceral fat accumulation stimulates the production of adipocytokines in patients with metabolic syndrome. Excess body weight gain during pregnancy is a risk factor for preeclampsia. To evaluate whether the pathogenesis of preeclampsia is similar to that of metabolic syndrome, we measured plasma adipocytokine concentrations and investigated the association between plasma adiponectin concentrations and body weight gain or endothelial function in preeclamptic women. We investigated 15 preeclamptic and 17 women with uncomplicated pregnancies. Women with preeclampsia had significantly lower plasma concentrations of adiponectin (10.2 \pm 2.0 vs. $\left.7.3 \pm 2.2 \mu \mathrm{g} \mathrm{ml}^{-1}, P<0.01\right)$, but higher concentrations of leptin, plasminogen activator inhibitor-1, interleukin-6, vascular cell adhesion molecule-1, E-selectin and C-reactive protein. Plasma triglyceride levels were significantly higher in preeclamptic patients, but the levels of other lipids did not differ significantly between the two groups. We found that flow-mediated vasodilation was significantly decreased in preeclamptic women compared with controls (10.6 \pm 6.4 vs. $3.8 \pm 2.0 \%, P<0.001$ ). Plasma adiponectin concentrations correlated negatively with body mass index $(r=-0.50, P<0.05)$ and body weight gain during pregnancy $(r=-0.63, P<0.01)$, and positively with flow-mediated vasodilation $(r=0.50, P<0.05)$ in preeclamptic women, but not in women with uncomplicated pregnancies. Similar to the patients with metabolic syndrome, we found that dysregulation of adipocytokines, such as low adiponectin levels and high levels of other adipocytokines, and excess body weight gain during pregnancy, may decrease plasma adiponectin concentrations that are associated with endothelial dysfunction in preeclamptic women.

Hypertension Research (2010) 33, 250-254; doi:10.1038/hr.2009.222; published online 15 January 2010

Keywords: adipocytokines; body weight gain; endothelial function; preeclampsia

\section{INTRODUCTION}

Preeclampsia, characterized by elevated blood pressure (BP) and proteinuria during pregnancy, is a leading cause of maternal death that is associated with complications such as cerebrovascular hemorrhage, and renal or hepatic failure. ${ }^{1}$ The vascular endothelium contributes to the regulation of vascular smooth muscle tone by producing vasoconstrictors, such as endothelin-1 and thromboxane, as well as vasodilators, such as prostacyclin and nitric oxide (NO). Endothelial cell injury and altered endothelial function are important in the pathogenesis of preeclampsia. ${ }^{2}$ In addition to endothelial dysfunction, preeclampsia has also been reported to be associated with insulin resistance, ${ }^{3}$ hyperlipidemia ${ }^{4}$ and an exaggerated vascular inflammatory response. ${ }^{5}$

Metabolic syndrome is a collection of atherosclerotic risk factors that includes obesity, insulin resistance, lipid disorders (especially hypertriglyceridemia) and hypertension.

Obesity is defined as an accumulation of excess body fat, but clinical studies have shown that body fat distribution, rather than the total amount of fat, is a determinant of obesity-related diseases. Several studies have reported that visceral adipose tissue accumulation may have a significant function in the development of metabolic syndrome $^{6,7}$ Adipocytokines are adipose tissue-derived bioactive substances, such as adiponectin, leptin, tumor necrosis factor- $\alpha$ (TNF- $\alpha$ ), plasminogen activator inhibitor-1 (PAI-1), free fatty acids (FFAs) and interleukin-6 (IL-6), produced preferentially by visceral adipose tissue compared with subcutaneous fat. Although visceral fat accumulation stimulates the production of adipocytokines, it decreases plasma adiponectin concentrations. Obese patients have decreased plasma adiponectin concentrations, whereas weight reduction is accompanied by an increase of this adipocytokine. ${ }^{8}$ Thus, plasma adiponectin concentrations correlate negatively with visceral fat volume. Adiponectin has been reported to be associated with insulin sensitivity, and hypoadiponectinemia may be linked to the onset of diabetes mellitus. ${ }^{9}$ In addition, adiponectin has protective effects on the vasculature, as it reduces the expression of cell adhesion molecules such as E-selectin, intercellular adhesion molecule (ICAM-1) and vascular cell adhesion molecule (VCAM-1), ${ }^{10}$ and suppresses the inflammatory response in endothelial cells. Accordingly, hypoadiponectinemia may induce vascular endothelial dysfunction. The association between obesity and preeclampsia is well documented. ${ }^{11}$ The pathogenesis of preeclampsia seems to be similar to that of metabolic syndrome, and it is reasonable to speculate that visceral fat 
accumulation during pregnancy may induce dysregulation of adipocytokines, leading to the development of preeclampsia.

In this study, we compared plasma concentrations of adipocytokines, metabolic syndrome-related parameters and endothelial function between women with uncomplicated pregnancies and preeclamptic women. We also investigated whether plasma adiponectin concentrations are correlated with body weight gain during pregnancy and endothelial function.

\section{METHODS}

\section{Study participants}

Between 1 April 2008 and 31 March 2009, we evaluated 15 Japanese women with preeclampsia and 17 Japanese women with uncomplicated pregnancies. These participants were recruited consecutively during the study period. Enrollment criteria for preeclampsia included BP above either $140 \mathrm{~mm} \mathrm{Hg}$ systolic or $90 \mathrm{~mm} \mathrm{Hg}$ diastolic after 20 weeks of gestation, and proteinuria of $30 \mathrm{mg}$ per $100 \mathrm{ml}$ or more. None of the preeclamptic participants presented with hemolysis, elevated liver enzymes and low platelet syndrome. Women with uncomplicated pregnancies, matched as a group for maternal age and gestational age, served as controls. All of the control women had a normal course of pregnancy and full-term delivery. None of the participants smoked, used caffeine or alcohol, had a history of thyroid disease, liver disease, diabetes mellitus, hypertension, hyperlipidemia or were currently taking any medication known to influence lipoprotein metabolism. We obtained written informed consent from each participant before admission to the study. The study design was approved by the Ethics Committee of Aichi Medical University.

\section{Adipocytokines, inflammatory markers, lipid concentrations, glucose and insulin}

Blood samples were collected from the participants between 0900 and 1100 hours after a 12-h fast. We analyzed serum concentrations of ICAM-1, VCAM-1, E-selectin, adiponectin, leptin, PAI-1 and FFAs by ELISA (SRL, Japan). The levels of total cholesterol, low-density lipoprotein (LDL), high-density lipoprotein (HDL) and total triglyceride in plasma were measured enzymatically. ${ }^{12,13}$ We analyzed the concentrations of high-sensitivity C-reactive protein (CRP) using the Behring Latex-Enhanced CRP assay on the Behring Nephelometer Analyzer System (Dade, Behring). The concentrations of IL-6 were measured by chemiluminescent enzyme immunoassay. We determined plasma glucose and insulin concentrations by the hexokinase technique and enzyme immunoassay (Tosoh Corp., Japan), respectively, and estimated insulin resistance from the fasting glucose and insulin levels. Homeostasis model assessment of insulin resistance was applied to evaluate fasting insulin resistance using the formula; fasting glucose ( $\mathrm{mg}$ per $100 \mathrm{ml}) \times$ fasting insulin $\left(\mu \mathrm{U} \mathrm{ml}^{-1}\right) / 405$.

\section{Endothelial function}

Patients rested in a supine position for $10 \mathrm{~min}$ before the study. High-resolution Doppler ultrasonography equipment (Sonovista-Color model MEU-1582, Mochida) with a $10-\mathrm{MHz}$ transducer was used to image the right brachial artery and measure vasodilatory responses. A non-tortuous segment of the brachial artery was scanned longitudinally $4-5 \mathrm{~cm}$ above the elbow, where the clearest image could be obtained. When an adequate transducer position was determined, the skin was marked and the arm was kept in a constant position throughout the study. After obtaining baseline images of the brachial artery and determining arterial flow velocity, a BP cuff encircling the proximal portion of the arm was inflated to $250 \mathrm{~mm} \mathrm{Hg}$ for $5 \mathrm{~min}$, and then suddenly deflated. Increased blood flow after sudden cuff deflation, termed reactive hyperemia, results in flow-mediated vasodilation (FMD) ${ }^{14}$ Flow velocity in the artery was determined again, and $1 \mathrm{~min}$ after cuff deflation, the brachial artery was imaged. BP and heart rate were monitored and recorded throughout the investigation. The diameter of the brachial artery was measured from the anterior to posterior interface between the media and adventitia (' $m$ ' line) at the end of diastole, incident with the $\mathrm{R}$ wave on a continuously recorded electrocardiogram. We determined the diameters for four cardiac cycles from images, and averaged these measurements. All scans were recorded on VHS videotape for later analysis. Vessel diameters were measured without knowledge of patient information. We calculated FMD as the percent increase in arterial diameter during hyperemia and used this as an index of endotheliumdependent vasodilation. ${ }^{15}$ In our laboratory, the intraobserver and interobserver variability for repeated measurements were $0.03 \pm 0.02$ and $0.05 \pm 0.03 \mathrm{~mm}$, respectively. The variability for FMD performed on 2 separate days was $2.1 \pm 0.9 \%$.

The plasma concentrations of adiponectin in the pregnant with hypertension and normal women were estimated 15.0 and $10.0 \mu \mathrm{g} \mathrm{ml}^{-1}$, respectively. Seventeen participants in each group needed to detect a significant difference under the statistical situation of $\alpha=0.05$ and $1-\beta=0.80$ with $15 \%$ dropout rate.

\section{Statistical analyses}

We used software 'SPSS' on the statistical analysis. Data are expressed as the mean \pm s.d. We analyzed differences in patient characteristics, serum concentrations of adipocytokines, lipids, and inflammatory markers, and FMD by Student's unpaired $t$-test when there was a normal distribution or by the Mann-Whitney test when the parameters were not normally distributed. Regression lines were determined by the least squares method. A level of $P<0.05$ was accepted as statistically significant.

\section{RESULTS}

The systolic and diastolic BPs and the plasma levels of uric acid, creatinine and hematocrit were all significantly elevated in preeclamptic participants. We found no significant difference between preeclamptic and control patients for maternal age, gestational age, body mass index (BMI), body weight gain during pregnancy, platelet counts, liver enzymes and blood urea nitrogen (Table 1).

Women with preeclampsia had significantly lower plasma concentrations of adiponectin $\left(7.3 \pm 2.2 v s .10 .2 \pm 2.0 \mu \mathrm{g} \mathrm{ml}^{-1}, P<0.01\right)$, but higher concentrations of leptin, PAI-1, IL-6, VCAM-1, E-selectin and CRP (Table 2). The preeclamptic participants had significantly higher plasma triglyceride levels, but the levels of other lipids did not differ significantly between the two groups. Plasma concentrations of blood glucose did not differ between the two groups, but insulin concentrations and insulin resistance were significantly greater in preeclamptic women (Table 3 ).

We found no significant difference in brachial artery diameter and blood flow between the two groups. The percent increase in blood flow induced by reactive hyperemia did not differ significantly, but FMD was significantly decreased in preeclamptic women compared with controls $(10.6 \pm 6.4$ vs. $3.8 \pm 2.0 \%, P<0.001$; Table 4).

\section{Table 1 Subjects characteristics}

\begin{tabular}{|c|c|c|c|}
\hline & Normal & Preeclampsia & $\mathrm{P}$ \\
\hline Age (years) & $30.9 \pm 0.7$ & $29.9 \pm 0.8$ & NS \\
\hline Gestational age (weeks) & $30.5 \pm 1.1$ & $29.3 \pm 1.0$ & NS \\
\hline $\mathrm{BMI}\left(\mathrm{kg} \mathrm{m}^{-2}\right)$ & $22.3 \pm 2.3$ & $23.3 \pm 2.5$ & NS \\
\hline Body weight gain (kg) & $5.5 \pm 3.9$ & $8.1 \pm 3.6$ & NS \\
\hline Systolic BP (mm Hg) & $104.9 \pm 16.3$ & $140.0 \pm 18.6$ & $<0.001$ \\
\hline Diastolic BP (mm Hg) & $52.1 \pm 11.3$ & $80.3 \pm 14.6$ & $<0.001$ \\
\hline Hematocrit (\%) & $32.1 \pm 1.8$ & $34.6 \pm 3.0$ & $<0.05$ \\
\hline Platelet $\left(\times 10^{4}\right)$ & $24.8 \pm 6.6$ & $24.3 \pm 3.9$ & NS \\
\hline AST $\left(\mid U^{-1}\right)$ & $9.2 \pm 5.2$ & $6.8 \pm 1.9$ & NS \\
\hline ALT $\left(\mid U^{-1}\right)$ & $15.1 \pm 3.4$ & $14.0 \pm 3.8$ & NS \\
\hline BUN (mg per $100 \mathrm{ml}$ ) & $8.8 \pm 1.0$ & $8.4 \pm 1.3$ & NS \\
\hline Creatinine (mg per $100 \mathrm{ml}$ ) & $0.35 \pm 0.06$ & $0.47 \pm 0.11$ & $<0.001$ \\
\hline Uric acid (mg per $100 \mathrm{ml}$ ) & $3.6 \pm 0.6$ & $5.6 \pm 1.4$ & $<0.001$ \\
\hline
\end{tabular}

Abbreviations: ALT, alanine aminotransferase; AST, asparate aminotransferase; BMI, body mass index; BP, blood pressure; BUN, blood urea nitrogen; NS, not significant. Data are expressed as mean \pm s.d. 
Table 2 Adipocytokine, cell adhesion molecules and C-reactive protein

\begin{tabular}{lccc}
\hline & Normal & Preeclampsia & P \\
\hline Adiponectin $\left(\mu \mathrm{g} \mathrm{ml}^{-1}\right)$ & $10.2 \pm 2.0$ & $7.3 \pm 2.2$ & $<0.01$ \\
Leptin $\left(\mathrm{ng} \mathrm{ml}^{-1}\right)$ & $10.0 \pm 4.4$ & $20.3 \pm 13.5$ & $<0.05$ \\
PAl-1 $\left(\mathrm{ng} \mathrm{ml}^{-1}\right)$ & $58.9 \pm 21.7$ & $111.6 \pm 45.6$ & $<0.01$ \\
IL-6 $\left(\mathrm{pg} \mathrm{ml}^{-1}\right)$ & $0.28 \pm 0.07$ & $0.37 \pm 0.10$ & $<0.01$ \\
FFA $\left(\mathrm{mEql}^{-1}\right)$ & $0.47 \pm 0.18$ & $0.40 \pm 0.22$ & $\mathrm{NS}$ \\
VCAM-1 $\left(\mathrm{ng} \mathrm{ml}^{-1}\right)$ & $629.6 \pm 133.0$ & $739.3 \pm 188.2$ & $<0.05$ \\
ICAM-1 $\left(\mathrm{ng} \mathrm{ml}^{-1}\right)$ & $203.6 \pm 29.6$ & $197.7 \pm 44.1$ & $\mathrm{NS}$ \\
E-selectin $\left(\mathrm{ng} \mathrm{ml}^{-1}\right)$ & $29.4 \pm 4.4$ & $39.9 \pm 20.3$ & $<0.05$ \\
C-reactive protein $\left(\mathrm{ng} \mathrm{ml}^{-1}\right)$ & $794.3 \pm 587.9$ & $1650.0 \pm 1766.2$ & $<0.05$ \\
\hline
\end{tabular}

Abbreviations: FFA, free fatty acids; ICAM, intercellular cell adhesion molecule; IL-6, interleukin-6; NS, not significant. PAI-1, plasminogen activator inhibitor-1; VCAM, vascular cell adhesion molecule.

Data are expressed as mean \pm s.d.

Table 3 Lipids and insulin resistance

\begin{tabular}{lccc}
\hline & Normal & Preeclampsia & P \\
\hline Total cholesterol (mg per $100 \mathrm{ml})$ & $261 \pm 37$ & $261 \pm 43$ & NS \\
Triglyceride $(\mathrm{mg}$ per $100 \mathrm{ml})$ & $174 \pm 59$ & $289 \pm 88$ & $<0.001$ \\
HDL cholesterol (mg per $100 \mathrm{ml})$ & $93 \pm 40$ & $73 \pm 10$ & $\mathrm{NS}$ \\
LDL cholesterol (mg per $100 \mathrm{ml})$ & $139 \pm 11$ & $130 \pm 9$ & $\mathrm{NS}$ \\
Fasting blood sugar $(\mathrm{mg}$ per $100 \mathrm{ml})$ & $76.9 \pm 20.4$ & $73.0 \pm 8.4$ & $\mathrm{NS}$ \\
Insulin $\left(\mu \mathrm{IU} \mathrm{ml}^{-1}\right.$ ) & $4.2 \pm 1.7$ & $7.3 \pm 9.3$ & $<0.001$ \\
Insulin resistance & $0.8 \pm 0.3$ & $1.3 \pm 1.7$ & $<0.01$ \\
\hline
\end{tabular}

Abbreviations: HDL, high-density lipoprotein; LDL, low-density lipoprotein; NS, not significant. Data are expressed as mean \pm s.d.

Table 4 Blood pressure, heart rate and brachial artery diameter and blood flow

\begin{tabular}{lccc}
\hline & Normal & Preeclampsia & P \\
\hline Systolic BP (mm Hg) & $103.8 \pm 16.4$ & $140.0 \pm 18.6$ & $<0.001$ \\
Diastolic BP (mm Hg) & $53.2 \pm 12.2$ & $80.6 \pm 16.9$ & $<0.001$ \\
Heart rate (beats min $\left.^{-1}\right)$ & $76.0 \pm 11.0$ & $76.5 \pm 5.0$ & NS \\
Baseline diameter $\left(\mathrm{mm}^{-}\right)$ & $3.4 \pm 0.3$ & $3.6 \pm 0.4$ & NS \\
Baseline flow $\left(\mathrm{ml} \mathrm{min}^{-1}\right)$ & $168 \pm 101$ & $179 \pm 409$ & NS \\
Hyperemic flow (\%) & $694 \pm 300$ & $575 \pm 321$ & NS \\
Flow-mediated vasodilation (\%) & $10.6 \pm 6.4$ & $3.8 \pm 2.0$ & $<0.001$ \\
\hline
\end{tabular}

Abbreviations: BP, blood pressure; NS, not significant.

Data are expressed as mean \pm s.d.

Plasma adiponectin concentrations correlated negatively with BMI $(r=-0.50, P<0.05)$ (Figure 1a) and body weight gain during pregnancy $(r=-0.63, P<0.01$ ) (Figure $1 b$ ), and positively with FMD $(r=0.50, P<0.05)$ in preeclamptic women (Figure 2$)$, but not in women with uncomplicated pregnancies.

\section{DISCUSSION}

Patients with metabolic syndrome often present with low adiponectin concentrations and high concentrations of other adipocytokines. ${ }^{16}$ Similarly, the results from our study showed that women with preeclampsia had increased plasma concentrations of leptin, PAI-1 and IL-6, but decreased concentrations of adiponectin.
As excess body weight gain during pregnancy has been reported to be a risk factor for preeclampsia, ${ }^{11}$ calorie restriction may be recommended to prevent the onset of preeclampsia. Although BMI and body weight gain during pregnancy did not differ between preeclamptic women and controls, they are both negatively correlated with plasma adiponectin concentrations in preeclamptic women. As decreased plasma adiponectin concentrations have been reported to be associated with increased visceral fat volume, ${ }^{16}$ our results suggest that visceral adipose tissue may accumulate during pregnancy in women with preeclampsia. The mechanism to decrease adiponectin production on accumulated visceral adipose tissue is regarded as TNF- $\alpha$-dependent pathway. TNF- $\alpha$, a major adipocytokine, is produced from visceral adipose tissue and act as a strong inhibitor of adiponectin promoter activity. ${ }^{17}$ Although we did not measure plasma concentrations of TNF- $\alpha$, low adiponectin concentrations might be explained by an increase in TNF- $\alpha$ secreted from accumulated visceral fat in preeclamptic women. In contrast, no significant association was found between adiponectin concentrations and BMI or body weight gain in the control group, indicating that subcutaneous fat rather than visceral fat may accumulate in women with uncomplicated pregnancies. Although visceral fat volume can be measured directly by CT scanning, it is contraindicated to pregnant women. On the basis of the results in this study, we can speculate that body weight gain because of excess visceral fat accumulation during pregnancy may induce the onset of preeclampsia and visceral fat-derived adipocytokines may contribute to the pathogenesis of preeclampsia.

PAI-1 mRNA levels increased up to 10 times in visceral adipose tissue, whereas it remained unchanged in the subcutaneous adipose tissue. ${ }^{18}$ According to Matsuzawa et al., ${ }^{18}$ plasma concentrations of PAI-1 are positively correlated with visceral fat volume. Thus, elevated plasma concentrations of PAI-1 secreted from visceral adipose tissue may be associated with an increased risk of thrombotic disorders in preeclamptic women.

Adiponectin regulates insulin sensitivity and glucose metabolism. ${ }^{9}$ Plasma adiponectin concentration shows an inverse correlation with insulin resistance ${ }^{19}$ and administration of recombinant adiponectin results in a significant decrease in plasma glucose concentrations. ${ }^{20}$ Adiponectin also has an anti-inflammatory effect by inhibiting the production of CRP. ${ }^{21}$ In this study, preeclamptic women had lower adiponectin concentrations and decreased insulin sensitivity, and increased plasma concentrations of CRP and IL-6. These results indicate that hypoadiponectinemia may be associated with insulin resistance and the stimulation of vascular inflammation in women with preeclampsia.

Decreased plasma adiponectin concentrations are observed in patients with vascular disorders such as obesity, diabetes mellitus and cardiovascular disease. Adiponectin may have an anti-atherogenic effect by reducing vascular damage. Adiponectin suppresses TNF- $\alpha$ induced endothelial adhesion molecule expression, the transformation of macrophages to foam cells, ${ }^{10}$ and TNF- $\alpha$ expression in macrophages and adipose tissue. ${ }^{22}$ In this study, plasma concentrations of VCAM-1 and E-selectin were elevated in preeclamptic women. Once cell adhesion molecules are expressed on the surface of endothelial cells or leukocytes following cytokine stimulation, they are shed within $24 \mathrm{~h}$. In contrast to adiponectin, CRP induces adhesion molecule expression, ${ }^{23}$ and elevated plasma levels of CRP may induce cell adhesion molecule expression in preeclamptic women. As plasma levels of cell adhesion molecules are associated with endothelial function, induced production of cell adhesion molecules may impair the endothelium in preeclamptic women. 

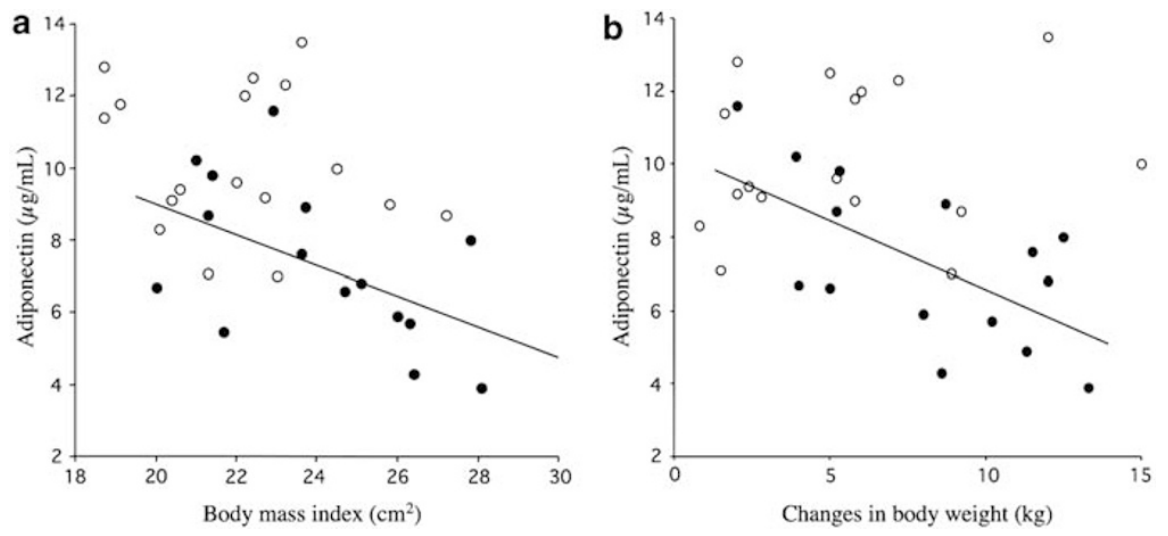

Figure 1 (a) Relationship between body mass index and plasma adiponectin concentrations. Open and closed circles indicate normal and pereeclamptic women, respectively. Normal, not significant; preeclampsia, $r=-0.50, P<0.05$. (b) Relationship between body weight gain and plasma adiponectin concentrations. Open and closed circles indicate normal and pereeclamptic women, respectively. Normal, not significant; preeclampsia, $r=-0.63, P<0.01$.

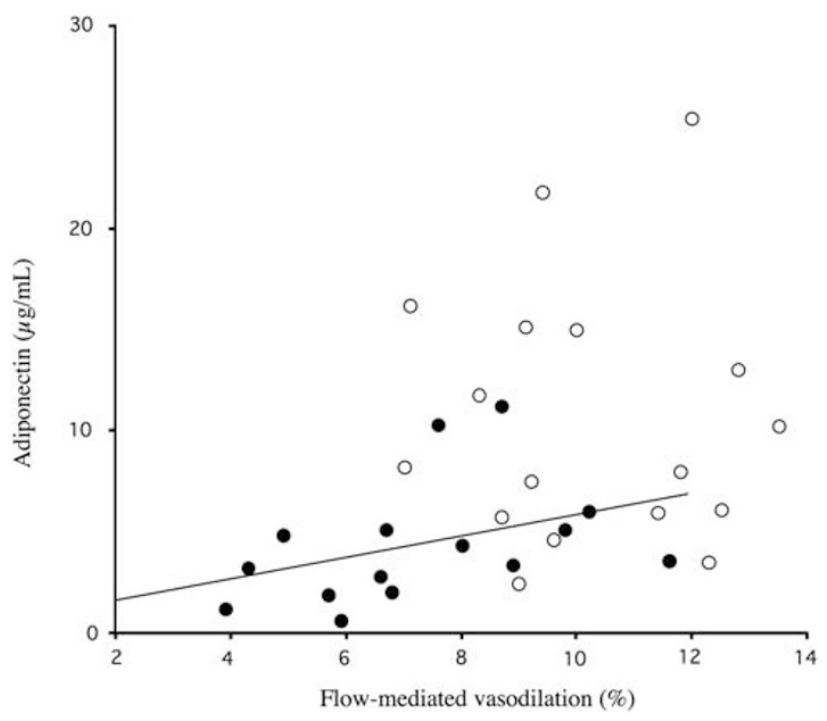

Figure 2 Relationship between flow-mediated vasodilation and plasma adiponectin concentrations. Open and closed circles indicate normal and pereeclamptic women, respectively. Normal, not significant; preeclampsia, $r=0.50, P<0.05$.

$\mathrm{NO}$, an endothelium-derived relaxing factor, is released in response to increased blood flow during reactive hyperemia. As several NO synthase inhibitors inhibit endothelium-dependent vasodilation, FMD appears to represent a vasodilation-dependent effect mediated by endothelium-derived NO. ${ }^{24}$ In our study, FMD was decreased in women with preeclampsia, indicating that endothelial function may be impaired. In addition, plasma adiponectin concentrations were positively correlated with FMD in preeclamptic women, but not in the control group. All together, these results suggest that decreased adiponectin concentrations may be associated with endothelial dysfunction in preeclamptic women through enhanced expression of endothelial cell adhesion molecules.

Decreased adiponectin concentrations in our study are consistent with some earlier reports, ${ }^{25,26}$ whereas other investigators ${ }^{27,28}$ have found high adiponectin concentrations in preeclamptic women. Ramsay et al. ${ }^{29}$ speculated that the elevation of adiponectin in preeclamptic women may be secondary to exaggerated non-specific adipocyte lipolysis or as a physiological response to enhance fat utilization. The authors, however, did not indicate the changes in body weight during pregnancy or the concentrations of other adipocytokines. Other possible explanations for the elevated adiponectin concentrations in preeclamptic women include reduced renal function and adiponectin resistance. In this study, plasma concentrations of adiponectin decreased, whereas concentrations of PAI-1, leptin and IL-6 increased in preeclamptic women. Although plasma adiponectin concentration may increase in women with severe preeclampsia, it may decrease in women with mild-to-moderate preeclampsia. Plasma adiponectin concentrations may depend on the severity of preeclampsia. As adiponectin is secreted from adipocytes, it is unlikely that increases in adiponectin levels occur simultaneously with other adipocytokines in preeclamptic women. Even if adiponectin concentrations increase, it may not have the proper physiological activities.

As visceral adipose tissue has high lipogenic and lipolytic activity, a large portion of the FFAs released from visceral adipose tissue is drained into the liver. In this study, plasma concentrations of FFAs did not increase in preeclamptic women, but might be elevated in the portal vein. Hepatic triglyceride synthesis and very low-density lipoprotein (VLDL) secretion are enhanced and plasma triglyceride levels are elevated in metabolic syndrome. In this study, plasma triglycerides, but not LDL or HDL were elevated in preeclamptic women. This suggests that accumulated visceral fat may stimulate the production of VLDL, resulting in increased plasma triglycerides in preeclamptic women. According to our earlier studies, women with preeclampsia have increased susceptibility of LDL particles. $^{30}$ Increased plasma triglyceride levels may reduce the size of LDL particles, making them more susceptible to oxidation. Although we did not measure the size of LDL particles, the elevation of plasma triglycerides observed in preeclamptic women may lead to decreased LDL particle diameter. As small or oxidized LDL particles have been reported to impair endothelial function, ${ }^{31}$ hypertriglyceridemia as well as hypoadiponectinemia may inhibit endothelial function in preeclamptic women.

In this study, we observed dysregulation of adipocytokines and endothelial dysfunction in preeclamptic women. According to our data, it is reasonable to speculate that excess visceral fat accumulation during pregnancy may induce the onset or development of preeclampsia. Although direct measurement of fat distribution is difficult in pregnant women, visceral fat can be measured by a recently developed non-invasive bioelectrical impedance technique. Further studies are needed to investigate whether excess visceral fat accumulates during pregnancy in preeclamptic women. 
1 MacKay AP, Berg CJ, Atrash HK. Pregnancy-related mortality from preeclampsia and eclampsia. Obstet Gynecol 2001; 97: 533-538.

2 Roberts JM, Redman CW. Pre-eclampsia: more than pregnancy-induced hypertension. Lancet 1993; 341: 1447-1451.

3 Wolf AM, Wolf $\mathrm{D}$, Rumpold $\mathrm{H}$, Enrich $\mathrm{B}$, Tilg $\mathrm{H}$. Adiponectin induces the antiinflammatory cytokines IL-10 and IL-1RA in human leukocytes. Biochem Biophys Res Commun 2004; 323: 630-635.

4 Gratacós E, Casals E, Sanllehy C, Cararach V, Alonso PL, Fortuny A. Variation in lipid levels during pregnancy in women with different types of hypertension. Acta Obstet Gynecol Scand 1996; 75: 896-901.

5 Benyo DF, Smarason A, Redman CW, Sims C, Conrad KP. Expression of inflammatory cytokines in placentas from women with preeclampsia. J Clin Endocrinol Metab 2001; 86: 2505-2512.

6 Fujioka S, Matsuzawa Y, Tokunaga K, Tarui S. Contribution of intra-abdominal fat accumulation to the impairment of glucose and lipid metabolism in human obesity. Metabolism 1987; 36: 54-59.

7 Kanai H, Matsuzawa Y, Kotani K, Keno Y, Kobatake T, Nagai Y, Fujioka S, Tokunaga K, Tarui S. Close correlation of intra-abdominal fat accumulation to hypertension in obese women. Hypertension 1990; 16: 484-490.

8 Esposito K, Pontillo A, Di Palo C, Giugliano G, Masella M, Marfella R, Giugliano D. Effect of weight loss and lifestyle changes on vascular inflammatory markers in obese women: a randomized trial. JAMA 2003; 289: 1799-1804.

9 Stefan N, Vozarova B, Funahashi T, Matsuzawa Y, Weyer C, Lindsay RS, Youngren JF, Havel PJ, Pratley RE, Bogardus C, Tataranni PA. Plasma adiponectin concentration is associated with skeletal muscle insulin receptor tyrosine phosphorylation, and low plasma concentration precedes a decrease in whole-body insulin sensitivity in humans. Diabetes 2002; 51: 1884-1888.

10 Ouchi N, Kihara S, Arita Y, Maeda K, Kuriyama H, Okamoto Y, Hotta K, Nishida M, Takahashi M, Nakamura T, Yamashita S, Funahashi T, Matsuzawa Y. Novel modulator for endothelial adhesion molecules: adipocyte-derived plasma protein adiponectin. Circulation 1999; 100: 2473-2476.

11 Weiss JL, Malone FD, Emig D, Ball RH, Nyberg DA, Comstock CH, Saade G, Eddleman K, Carter SM, Craigo SD, Carr SR, D'Alton ME, FASTER Research Consortium. Obesity, obstetric complications and cesarean delivery rate-a population-based screening study. Am J Obstet Gynecol 2004; 190: 1091-1097.

12 Allain CC, Poon LS, Chan CS, Richmond W, Fu PC. Enzymatic determination of total serum cholesterol. Clin Chem 1974; 20: 470-475.

13 Ikeda T, Shibuya Y, Senba U, Sugiuchi H, Araki S, Uji Y, Okabe H. Automated immunoturbidimetric analysis of six plasma apolipoproteins: correlation with radial immunodiffusion assays. J Clin Lab Anal 1991; 5: 90-95.

14 Rubanyi GM, Romero JC, Vanhoutte PM. Flow-induced release of endothelium-derived relaxing factor. Am J Physiol 1986; 250: H1145-H1149.

15 Stein JH, Keevil JG, Wiebe DA, Aeschlimann S, Folts JD. Purple grape juice improves endothelial function and reduces the susceptibility of LDL cholesterol to oxidation in patients with coronary artery disease. Circulation 1999; 100: 1050-1055.
16 Matsuzawa Y. The role of fat topology in the risk of disease. Int J Obes (Lond) 2008; 32: S83-S92.

17 Maeda N, Takahashi M, Funahashi T, Kihara S, Nishizawa H, Kishida K, Nagaretani H, Matsuda M, Komuro R, Ouchi N, Kuriyama H, Hotta K, Nakamura T, Shimomura I, Matsuzawa Y. PPARgamma ligands increase expression and plasma concentrations of adiponectin, an adipose-derived protein. Diabetes 2001; 50: 2094-2099.

18 Matsuzawa Y, Funahashi T, Kihara S, Shimomura I. Adiponectin and metabolic syndrome. Arterioscler Thromb Vasc Biol 2004; 24: 29-33.

19 Weyer C, Funahashi T, Tanaka S, Hotta K, Matsuzawa Y, Pratley RE, Tataranni PA. Hypoadiponectinemia in obesity and type 2 diabetes: close association with insulin resistance and hyperinsulinemia. J Clin Endocrinol Metab 2001; 86: 1930-1935.

20 Hara K, Boutin P, Mori Y, Tobe K, Dina C, Yasuda K, Yamauchi T, Otabe S, Okada T, Eto K, Kadowaki H, Hagura R, Akanuma Y, Yazaki Y, Nagai R, Taniyama M, Matsubara K, Yoda M, Nakano Y, Tomita M, Kimura S, Ito C, Froguel P, Kadowaki T. Genetic variation in the gene encoding adiponectin is associated with an increased risk of type 2 diabetes in the Japanese population. Diabetes 2002; 51: 536-540.

21 Ouchi N, Kihara S, Funahashi T, Nakamura T, Nishida M, Kumada M, Okamoto $Y$ Ohashi K, Nagaretani H, Kishida K, Nishizawa H, Maeda N, Kobayashi H, Hiraoka H, Matsuzawa Y. Reciprocal association of C-reactive protein with adiponectin in blood stream and adipose tissue. Circulation 2003; 107: 671-674.

22 Okamoto Y, Arita Y, Nishida M, Muraguchi M, Ouchi N, Takahashi M, Igura T, Inui Y, Kihara S, Nakamura T, Yamashita S, Miyagawa J, Funahashi T, Matsuzawa Y. An adipocyte-derived plasma protein, adiponectin, adheres to injured vascular walls. Horm Metab Res 2000; 32: 47-50.

23 Pasceri V, Willerson JT, Yeh ET. Direct proinflammatory effect of C-reactive protein on human endothelial cells. Circulation 2000; 102: 2165-2168.

24 Joannides R, Haefeli WE, Linder L, Richard V, Bakkali EH, Thuillez C, Lüscher TF. Nitric oxide is responsible for flow-dependent dilatation of human peripheral conduit arteries in vivo. Circulation 1995; 91: 1314-1319.

25 Ouyang $\mathrm{Y}$, Chen $\mathrm{H}$, Chen $\mathrm{H}$. Reduced plasma adiponectin and elevated leptin in preeclampsia. Int J Gynaecol Obstet 2007; 98: 110-114.

26 Shinohara K, Wakatsuki A, Watanabe K, Ikenoue N, Fukaya T. Plasma adiponectin concentrations in women with preeclampsia. Hypertension 2004; 43: e17.

27 Suwaki N, Masuyama H, Nakatsukasa H, Masumoto A, Sumida Y, Takamoto N, Hiramatrsu Y. Hypoadiponectinemia and circulating angiogenic factors in overweight patients complicated with pre-eclampsia. Am J Obstet Gynecol 2006; 195: 1687-1692.

28 Nien JK, Mazaki-Tovi S, Romero R, Erez O, Kusanovic JP, Gotsch F, Pineles BL, Gomez R, Edwin S, Mazor M, Espinoza J, Yoon BH, Hassan SS. Adiponectin in severe preeclampsia. J Perinat Med 2007; 35: 503-512.

29 Ramsay JE, Jamieson N, Greer IA, Sattar N. Paradoxical elevation in adiponectin concentrations in women with preeclampsia. Hypertension 2003; 42: 891-894.

30 Wakatsuki A, Ikenoue N, Okatani Y, Shinohara K, Fukaya T. Lipoprotein particles in preeclampsia: susceptibility to oxidative modification. Obstet Gynecol 2000; 96 : 55-59.

31 Stewart DJ, Monge JC. Hyperlipidaemia and endothelial dysfunction. Curr Opin Lipidol 1993; 4: 319-324. 